\title{
A combined mathematical geophysical model for prediction of pyrite oxidation and pollutant leaching associated with a coal washing waste dump
}

\author{
${ }^{1 *}$ F. Doulati Ardejani; ${ }^{1}$ B. Jodieri Shokri; ${ }^{1}$ A. Moradzadeh; ${ }^{2}$ E. Soleimani; ${ }^{1}$ M. Ansari Jafari \\ ${ }^{1}$ Faculty of Mining, Petroleum and Geophysics, Shahrood University of Technology, Shahrood, Iran \\ ${ }^{2}$ Faculty of Chemistry, Shahrood University of Technology, Shahrood, Iran
}

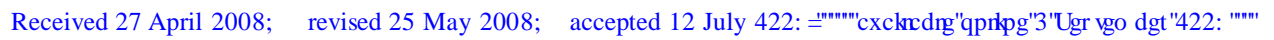

\begin{abstract}
The waste produced by coal washing process produces many environmental problems. In this study, the pollution problems associated with the waste produced by Alborz Sharghi Coal Washing Plant was investigated by mathematical modeling. The study area is located at $11 \mathrm{~km}$. to Razmjah coal region and $45 \mathrm{~km}$. to Tehran-Mashhad road in the north part od Iran. To achieve the goal, a few samples were taken from different depths at three points on the waste dump in order to investigate pyrite oxidation and pollution generation. The samples were then analysed, using an AA-670 Shimadzu atomic absorption to determine the fraction of pyrite remained within the waste particles. A numerical finite volume model using Phoenics package has been developed to simulate pyrite oxidation and pollution generation from the Alborz Sharghi coal washing waste dump. The pyrite oxidation reaction is described by the shrinking-core model. Gaseous diffusion is the main mechanism for the transport of oxygen through the waste. The results of numerical modelling were compared with the field observations and close agreement was achieved. A simple mathematical model incorporating advection and hydrodynamic dispersion processes was also presented in order to verify the results of geophysical time-laps method showing transportation of the pollutants through the downstream of the waste dump. Both mathematical model and geophysical time-laps method are agreed in the identification of pollutant transport emanated from the waste dump. The results of such investigations can be used for designing an effective environmental management program.
\end{abstract}

Key words: Numerical model, finite volume, geo-electrical method, time-laps technique, pollution

\section{INTRODUCTION}

Coal mines have made considerable contribution to Iranian mining industry and the national economy. Coal is considered to be a major mineral which is used to generate energy. The coal produced by mining activity should be washed in order to raise its quality and remove any impurity. Mining activities and subsequent coal washing program produce a number of environmental problems. The groundwater pollution problem is the adverse effect, which may be caused by the pyrite oxidation, acid mine drainage (AMD) generation and subsequence pollutant leaching from the coal washing dumps. The groundwater pollution may start during the mining operation and mineral processing stages and it will be continued after abandonment of the mine and waste dumps if no attempt is made to prevent it. Fig. 1 shows a schematic 凶*Corresponding Author Email: fdoulati@shahroodut.ac.ir Tel./Fax:+98 2733335509 diagram of waste dump position which is located in Mehmandoost region at about $400 \mathrm{~km}$. north-east of Tehran in Semnan province. AMD results at waste dumps from the oxidation of certain sulphide minerals in particular pyrite (Atkins and Pooley, 1982). The overall stoichiometric reaction describing the oxidation of pyrite and AMD generation is given as:

$$
2 \mathrm{FeS}_{2}+\frac{15}{2} \mathrm{O}_{2}+\mathrm{H}_{2} \mathrm{O} \rightarrow 2 \mathrm{Fe}^{3+}+4 \mathrm{SO}_{4}{ }^{2-}+2 \mathrm{H}^{+}
$$

As Eq. 1 shows, pyrite can be oxidised with direct oxidation of pyrite by $\mathrm{O}_{2}$, forming $\mathrm{Fe}^{2+}, \mathrm{SO}_{4}^{-2}$ and $\mathrm{H}^{+}$ (Singer and Stumm, 1970; Rogowski et al., 1977; Williams et al., 1979; Guedes et al., 1986). Fig. 2 shows a schematic diagram describing pyrite oxidation and subsequent pollutants leaching from a waste dump. Fig. 2 identifies oxygen diffusion, pyrite oxidation in 


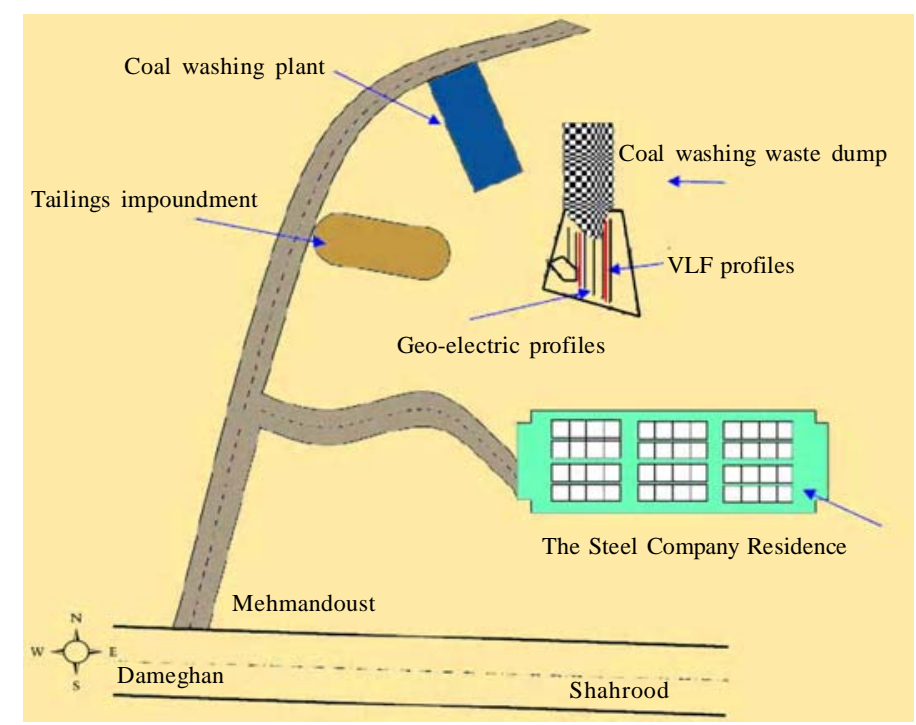

Fig. 1: Schematic diagram of coal washing waste dump site

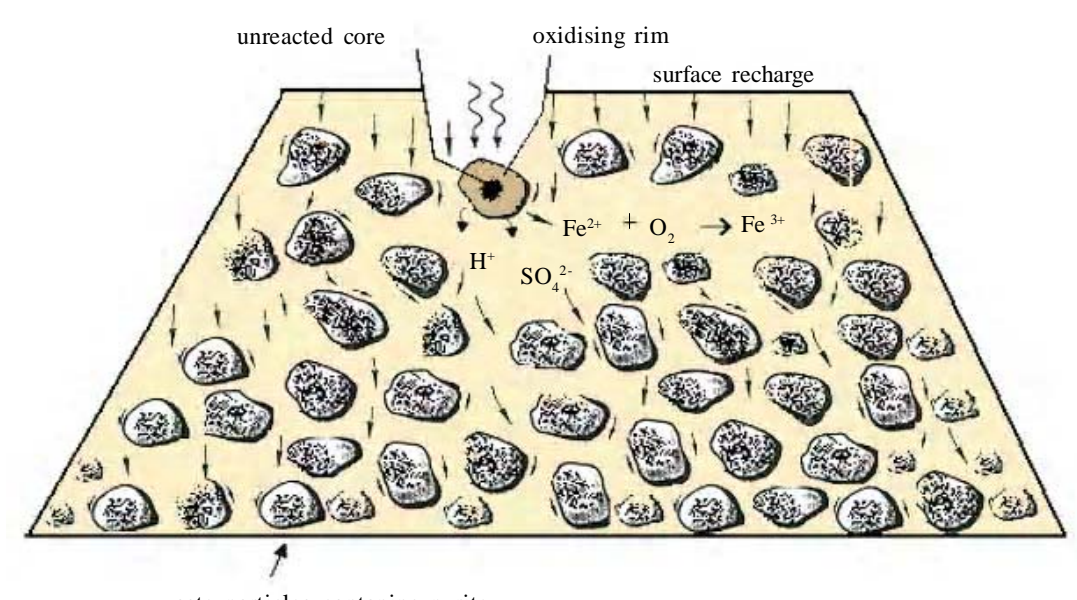

waste particles contaning pyrite

Fig. 2: Schematic diagram representing pyrite oxidation and pollutants leaching from a coal waste dump

waste materials, surface recharge, chemical reactions and the transport of oxidation products through coal waste materials. Although not considered in this study, the oxidation of $\mathrm{Fe}^{2+}$ produces $\mathrm{Fe}^{3+}$, consuming $\mathrm{O}_{2}$ within the particles. Oxygen diffuses from zones of higher oxygen concentration to zones of lower oxygen concentration through the air-filled pore space in the waste materials.

Although considerable effort has been made to model the pyritic oxidation and pollution generation, the focus is mainly on the pyrite oxidation and leaching processes from waste rock dumps (Cathles and Apps,
1975; Cathles, 1979; Davis and Ritchie, 1986; Davis et al., 1986; Lefebvre and Gelinas, 1995; Destouni et al., 1998), open cut mines (Jaynes et al., 1984a, b; Doulati Ardejani et al., 2004; Singh and Doulati Ardejani, 2004) and mine tailings (Elberling et al., 1994; Wunderly et al., 1996; Walter et al., 1994a, b). Despite many research works have been done related to mine tailings, none of them is directly relevant to the coal washing waste dumps in order to quantify the mechanisms that control the rate of pyrite oxidation and the subsequent leaching of the reaction products from coal washing waste dump. Hence, there is a need to develop a model 
describing the long-term oxidation of pyrite and leaching processes involved in a coal washing waste dump. The amount of pollutants produced in waste dump sites can be reduced by using efficient reclamation techniques during the operation of coal washing plants and also after cessation of processing operations. However, the assessment and development of best reclamation and management techniques in order to minimise the effect of waste dump site on the hydrology and hydrogeology of the area is a long-term and expensive procedure. The development of a numerical model that describes pyrite oxidation and pollution generation from the waste dump sites would facilitate the development of a waste dump rehabilitation and environmental management plan during the design stage of a coal washing plant. In order to achieve this goal, a numerical finite volume model (Patankar, 1980; Putti et al., 1990) using PHOENICS (Spalding, 1981) as a computational fluid dynamic, CFD, (Edwards et al., 1995; Versteeg and Malalasekera, 1995) is developed to predict pollution potential with particular reference to the long term pyrite oxidation and pollutant leaching into surface and groundwater flow system. The mathematical modeling predictions are compared with those results obtained using a geophysical time-laps method (Lock, 1999a, b) in the identification of pollutant transportation process through the subsurface porous medium. The objective of this paper is to develop a model for prediction of pyrite oxidation problems in coal washing waste dump.

\section{MATERIALS AND METHODS}

Site description

The study area is a part of Tazareh coal region and is located in the Shahrood with 1:100,000 geological sheet. From geological point of view, the area consists of sandstone, thin bedded coaly shale of Shemshak formation, new alluvial deposits and old alluvial fan with gravel marl and quartz. The environmental study in the area was started in July 2005 and completed in July 2006. Coal in the region is mined by the Alborz Sharghi coal company. Alborz Sharghi Coal Washing Plant has being worked for 30 years. The coal extracted from Tazareh, Gheshlagh and Tabas coal deposits are washed in this plant. The processed coal is then being transported to Isfahan and is used in steel company. The input feed of the washing plant is 600, 000 ton per year. The coal recovery in the plant is $50 \%$. The rest of the input feed is transported from the tailings impoundment by trucks and dumped as waste materials at the immediate distance from the washing plant. Depending on the method is being used for coal washing, two kind of the waste are produced and dumped in distinct places. These are the waste produced by jig machine and that produced by flotation process. It has been expected that the amount of the coal waste in the study area to be about 3 million tons. Table 1 gives a general description and characteristics of the coal waste dump in the study site.

The average elevation of the site is $2600 \mathrm{~m}$; ; having a moderate topographical condition. The main access road to the study area is Mehmandoust - Tazareh coal mine road. The average annual precipitation at the site was $253 \mathrm{~mm}$. The nearby lands of the area (about $10 \mathrm{~km}$ far from the site) are under agricultural activities. The study area can be important for the wild life. The temperature varies from about $40{ }^{\circ} \mathrm{C}$ in summer to $-15^{\circ} \mathrm{C}$ in winter.

\section{Method of the study}

15 coal waste samples each $4 \mathrm{~kg}$ in weight were taken from different depths at three points on the dump in order to investigate pyrite oxidation and pollutant generation (Table 2). The samples were first sieved in the mineral processing laboratory at Shahrood University of Technology to obtain a particle size $<75 \mu$. $\mathrm{HCl}$ acid was used to dissolve sulphates. Pyrite was extracted from the coal using $\mathrm{HNO}_{3}$ acid. An AA-670 Shimadzu atomic absorption was used to measure iron from the solution, then employed to determine the fraction of pyrite remaining within the waste particles. For geophysical studies, a portable WADI instrument (ABEM 2000) was used to measure very low frequency (VLF) data. The geo-electrical data were measured using ABEM SAS 1000 C instrument.

\section{Model theory}

The oxidation of pyrite within waste dump sites can be described by the shrinking-core model (Levenspiel, 1972; Cathles and Apps, 1975; Jaynes et al., 1984a, b; Lefebvre and Gelinas, 1995). Considering that the Equation 1 is the only important mechanism for AMD generation and assuming that the particles containing pyrite are spherical and all particles have equal size and noting that oxygen is the only oxidant participates in the pyrite oxidation process, the model reduces to: 
Table 1: General description and characteristics of the jig machine coal waste dump observed in the study area

\begin{tabular}{ll}
\hline Parameter & Value \\
\hline Dump surface area & $137500 \mathrm{~m}^{2}$ \\
Dump height & $20 \mathrm{~m}$ \\
Permeability of the dump & $23-54 \mathrm{~mm} / \mathrm{h}$ \\
$\begin{array}{l}\text { Average fraction of pyrite in the } \\
\text { waste materials }\end{array}$ & $1.7 \%$ \\
$\begin{array}{l}\text { Weathering condition } \\
\text { Stability condition }\end{array}$ & $\begin{array}{l}\text { considerable in surface layers } \\
\text { Waste size }\end{array}$ \\
\hline
\end{tabular}

Table 2: Sample descriptions

\begin{tabular}{lll}
\hline Location & Depth $(\mathrm{m})$ & Number of samples \\
\hline No. 1 & $0,0.2,0.55,1.1,1.5$ & 5 \\
No. 2 & $0,0.2,0.5,1.1,1.5,1.6$ & 6 \\
No. 3 & $0,0.2,0.5,1.1,1.5$ & 5 \\
\hline
\end{tabular}

$$
\frac{\partial X}{\partial t}=\frac{-3 X^{\frac{2}{3}}}{6 \tau_{D} X^{\frac{1}{3}}\left(1-X^{\frac{1}{3}}\right)+\tau_{C}}
$$

In Eq. 2, $\tau_{D}$ and $\tau_{C}$ can be calculated from the following expressions (Levenspiel, 1972):

$$
\begin{gathered}
\tau_{D}=\frac{\rho R^{2}}{6 b D_{e} C} \\
\tau_{C}=\frac{\rho R}{b K \alpha \lambda C}
\end{gathered}
$$

where,

$X=$ fraction of pyrite remaining in the waste dump after some leaching $(\mathrm{kg} / \mathrm{kg})$;

$K=$ first-order surface reaction rate constant $(\mathrm{m} / \mathrm{s})$;

$\alpha=$ surface area of pyrite per unit volume of waste particle $\left(\mathrm{m}^{-1}\right)$;

$\mathrm{C}=$ oxygen concentration in the water surrounding the particle $\left(\mathrm{mol} / \mathrm{m}^{3}\right)$;

$\mathrm{b}=$ stoichiometric ratio of pyrite to oxygen consumption ( $\mathrm{mol} / \mathrm{mol})$;

$\rho=$ density of pyrite in the particle $\left(\mathrm{mol} / \mathrm{m}^{3}\right)$;

$R=$ particle radius $(\mathrm{m})$;

$\lambda=$ reaction skin depth $(\mathrm{m})$;
$\tau_{D}=$ time required for full oxidation of pyrite in diffusion controlled reaction (s);

$\tau_{C}=$ time required for complete oxidation of pyrite by surface reaction kinetics (s);

$t=$ time $(s)$;

$D_{e}=$ oxygen diffusion coefficient in water $\left(\mathrm{m}^{2} / \mathrm{s}\right)$.

The concentration of oxygen within the pore spaces of the dump can be converted to the liquid phase using Henry's law and the gas law (Davis and Ritchie, 1986; Davis et al., 1986). Furthermore, the reaction skin depth was determined from the pyritic surface area, surface reaction rate constant and oxygen diffusion coefficient in the solution phase as presented by Cathles and Apps (1975). In this study, the value of $\alpha$ was calculated $100 / m$. This takes into account particles containing reactive pyrite as spheres. $\alpha$ in Eq. 4 is recalculated using Eq. 5 to incorporate the reduction in surface area of pyrite as time progresses (Elberling et al., 1994):

$\alpha_{t}=\alpha_{t-1}-K \Delta t / \rho$

where,

$\Delta t=$ time-step;

$K$ = first-order rate constant for $\mathrm{FeS}_{2}$ consumption;

$\alpha_{t-1}=$ pyrite surface area at previous time step.

Oxygen is transported through the waste dump by the process of diffusion. It is assumed that the oxygen is only consumed by the pyrite oxidation reaction and no bacterial activity was allowed to take place within the waste materials. The governing equation of oxygen transport incorporating the volumetric consumption term at steady-state conditions can be expressed as:

$$
D_{1} \frac{\partial^{2} u}{\partial z^{2}}+\frac{-3(1-\phi) b^{-1} \rho X^{\frac{2}{3}}}{6 \tau D X^{\frac{1}{3}}\left(1-X^{\frac{1}{3}}\right)+\tau_{C}}=0
$$

where,

$D_{1}=$ effective diffusion coefficient of oxygen within $\operatorname{dump}\left(\mathrm{m}^{2} / \mathrm{s}\right)$

$\mathrm{Z}=\operatorname{depth}(\mathrm{m})$;

$u=$ oxygen concentration within the pore space of spoil; 
$\phi=$ porosity of dump.

The volumetric consumption term in Eq. 6 which is due to the pyrite oxidation reaction, was modified from Eq. 2 by taking into account the molar density of pyrite in waste $(\rho)$ and the stoichiometric ratio of pyrite consumption to oxygen consumption (b) (Jaynes et al., 1984a).

\section{Modeling tool}

To solve the partial differential Eqs. 2 and 6 incorporating finite volume method, PHOENICS package was used. PHOENICS is a general-purpose CFD package which can be used for simulation of fluid flow, heat transfer, mass transfer and associated chemical reactions as well as stress analysis in solids (Spalding, 1981). The readers are referred to Doulati Doulati Ardejani et al. (2004) for more details about the PHOENICS model, its modules and capabilities.

The partial differential equation solved by PHOENICS in a single-phase problem is given by (Spalding, 1981):

$\frac{\partial}{\partial t}(\rho \phi)+\frac{\partial}{\partial x_{j}}\left(\rho u_{j} \phi-\Gamma_{\phi} \frac{\partial \phi}{\partial x_{j}}\right)=S_{\phi}$

where,

$\phi=$ any dependent variable;

$t=$ time (s);

$r_{i}=$ volume fraction of phase $i$;

$\rho=$ PHOENICS-term for density;

$u_{j}=$ velocity component in the $x_{j}$ direction;

$\Gamma_{\phi}=$ diffusive exchange coefficient for $\Phi$;

$\mathrm{X}_{\mathrm{j}}=$ Cartesian coordinates;

$\mathrm{S}_{\Phi}=$ source rate of $\Phi$.

It should be noted that the general source term $\mathrm{S}_{\Phi}$ can include all terms other than diffusion, convection and transient terms in the Eq. 7. Since Eqs. 2 and 6 contain terms which are not incorporated in PHOENICS solver; therefore they should be implemented in PHOENICS by introducing the appropriate setting for each term in the Q1 file and applying extra FORTRAN coding in the GROUND subroutine. The modified PHOENICS solver (modified EARTH) can be then linked and solved when the GROUND subroutine is compiled using Compaq visual FORTRAN compiler.

\section{Modeling setting}

In the present model, a one-dimensional simulation was performed using PHOENICS software. The model input data are given in Table 3. A waste profile with a depth of $5 \mathrm{~m}$. was divided into 30 equal size control volumes. The surface of the waste dump was initially specified as a first type boundary condition with the oxygen concentration equal to the atmospheric concentration, 0.21 mole fraction $\left(\approx 9 \mathrm{~mol} / \mathrm{m}^{3}\right)$. At the base of the spoil column, a zero-gradient boundary condition was assigned. It was further assumed that no oxygen initially exists within the profile. An initial value of $1.6 \%$ was specified for the pyrite oxidation model to describe the initial distribution of the pyrite within the waste throughout the profile.

\section{RESULTS AND DISCUSSION}

Fig. 3 illustrates the percent of pyrite remained within the waste particles versus depth. Simulation time is 1 year. In this diagram the modeling result is shown in solid line and is compared with field data shown as data points. This comparison was made for sample No. 1. As evident from the Fig. 3, the model prediction is different from those data obtained from the field. The difference between modeling results and the field data may be related to the errors arising during sampling and analysing process. Furthermore, this difference may due to the fact that the position of this sampling point (No. 1) was selected in a part of the coal washing waste that was covered by recent materials.

Fig. 4 compares the model predictions (solid line) and field measurements (data points) for the percent of pyrite remained in waste particles of the entire spoil column. This comparison is for the sampling point No. 2 over the waste dump. As it is clear, the agreement between modeling results and field data is somewhat close. Both simulation results and field observations showed that the rate of pyrite oxidation decreased sharply at lower depths up to $0.5 \mathrm{~m}$. where oxygen concentration decreased rapidly. For an effective diffusion coefficient of $5 \times 10^{-8} \mathrm{~m}^{2} / \mathrm{s}$ and a simulation time of about 1 year, pyrite oxidation decreased gradually for depths between $0.5-1.2 \mathrm{~m}$. and for deeper layers (below $1.2 \mathrm{~m}$.) where no oxygen is available to oxidise pyrite, the pyrite oxidation reaction was completely ceased.

The percent of pyrite remained within the waste particles of spoil profile for sample point No. 3 is shown in Fig. 5. As it is illustrated well, the model predictions 
F. Doulati Ardejani et al.

Table 3: Parameters used for the simulation

\begin{tabular}{lll}
\hline Parameter & Value & Reference \\
\hline effective diffusion coefficient $\left(\mathrm{m}^{2} / \mathrm{s}\right)$ & variable $\left(1 \times 10^{-8}-1 \times 10^{-6}\right)$ & Elberling et al. 1994 \\
pyrite fraction $(\%)$ & $(1.6-1.8)$ & 2300 \\
bulk density of spoil $\left(\mathrm{kg} / \mathrm{m}^{3}\right)$ & $23\left(5900 \mathrm{~kg} / \mathrm{m}^{3}\right)$ & Jaynes et al. $1984 \mathrm{~b}$ \\
molar density of pyrite within particle $\left(\mathrm{mol} / \mathrm{m}^{3}\right)$ & 100 \\
surface area of pyrite per unit volume of spoil/m. & $2 \times 10^{-6}$ & Jaynes et al., 1984b \\
diameter of particles (m.) & $8.3 \times 10^{-10}$ & Jaynes et al., 1984b \\
first-order rate constant for oxygen $(\mathrm{m} . / \mathrm{s})$ & $1.0 \times 10^{-11}$ & 0.25 \\
diffusion coefficient of oxygen in water $\left(\mathrm{m}^{2} / \mathrm{s}\right)$ & 5 \\
recharge value $(\mathrm{m} . / \mathrm{y})$ & $2-5$ \\
waste column depth (m.) & 24 \\
simulation time $(\mathrm{y})$ & 30 \\
number of iterations & 0.17 \\
cell numbers & \\
size of each control volume $(\mathrm{m})$. & & \\
\hline
\end{tabular}

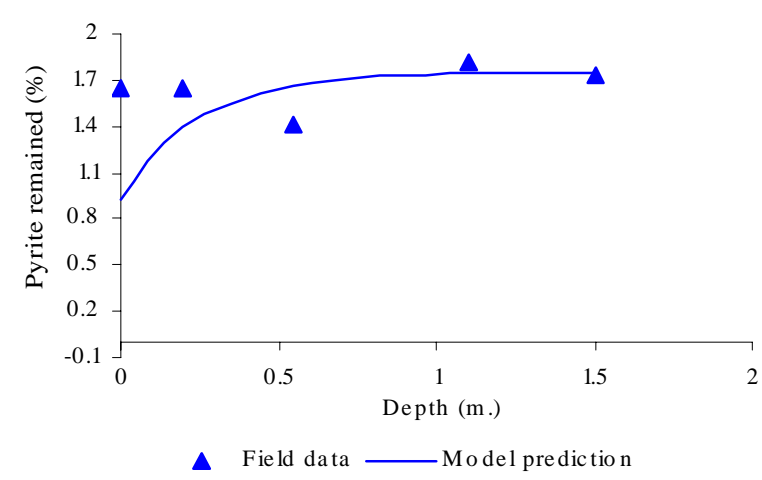

Fig. 3: Comparison of the field data and modeling results of the fraction of pyrite remained as a function of depth for sample No. 1

are in good agreement with the field data. For lower depths (up to $0.25 \mathrm{~m}$.) where the concentration of oxygen decreased dramatically, pyrite oxidation also decreased sharply. It decreased again but at a slower rate in the zone between $0.25 \mathrm{~m}$. and $0.5 \mathrm{~m}$. Below this depth the pyrite oxidation process decreased gradually up to $1.2 \mathrm{~m}$. The oxidation of pyrite was then ceased for depths bellower than $1.5 \mathrm{~m}$. due to the lack of oxygen. The results illustrated in Figs. 3 to 5 were obtained for an effective diffusion coefficient of $5 \times 10^{-8} \mathrm{~m}^{2} / \mathrm{s}$ in oxygen transport model. As it is evident from Fig. 6, the pyrite oxidation reaction consumed oxygen within the waste dump profile and resulted in steeper gradients and oxygen decreased linearly from the dump surface to the reaction front. Sensitivity analyses of the major parameters that influence the rate of the pyrite oxidation have been carried out by performing several simulations. Although the sensitivity of the model major parameters such as effective diffusion coefficient of oxygen transport, radius of waste particles containing pyrite,

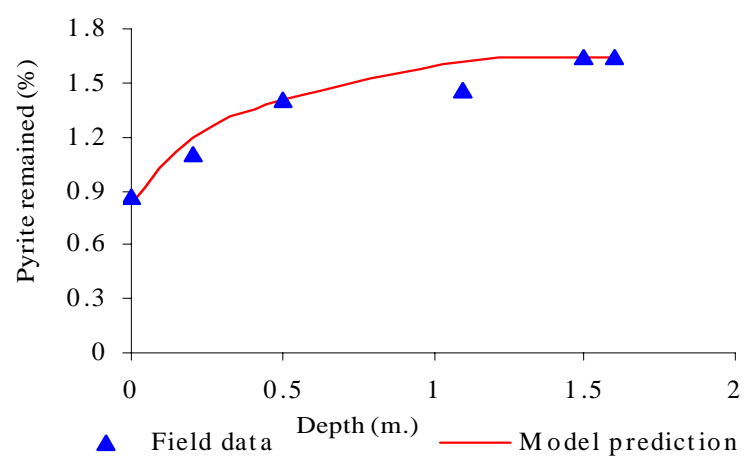

Fig. 4: Comparison of the field data and modeling results of the fraction of pyrite remained as a function of depth for sample No. 2

pyrite content and the oxidation time were evaluated, this paper only contains the effects of effective diffusion coefficient of oxygen transport model and the simulation time on the rate of pyrite oxidation process. The field results of sample point No. 2 was selected for performing the sensitivity analysis.

The first simulation was carried out to take into account the sensitivity of the model to changes in oxygen diffusion coefficient. The effective diffusion coefficients ranged from a low value $\left(1 \times 10^{-8} \mathrm{~m}^{2} / \mathrm{s}\right)$ to a high value representing well-drained waste conditions $\left(1 \times 10^{-6}\right.$ $\mathrm{m}^{2} / \mathrm{s}$ ). As Fig. 6 shows, under the low diffusion value $\left(1 \times 10^{-8} \mathrm{~m}^{2} / \mathrm{s}\right)$ oxygen penetrated less than $1 \mathrm{~m}$. within 1 year compared with the well-drained waste condition where the oxygen diffused more than $4 \mathrm{~m}$. of the waste profile over the same time period. It is evident from Fig. 6 that the concentration of oxygen is most sensitive to the effective diffusion coefficient. As effective diffusion coefficient increased, oxygen diffused at deeper layers and consequently it increased the rate of pyrite 


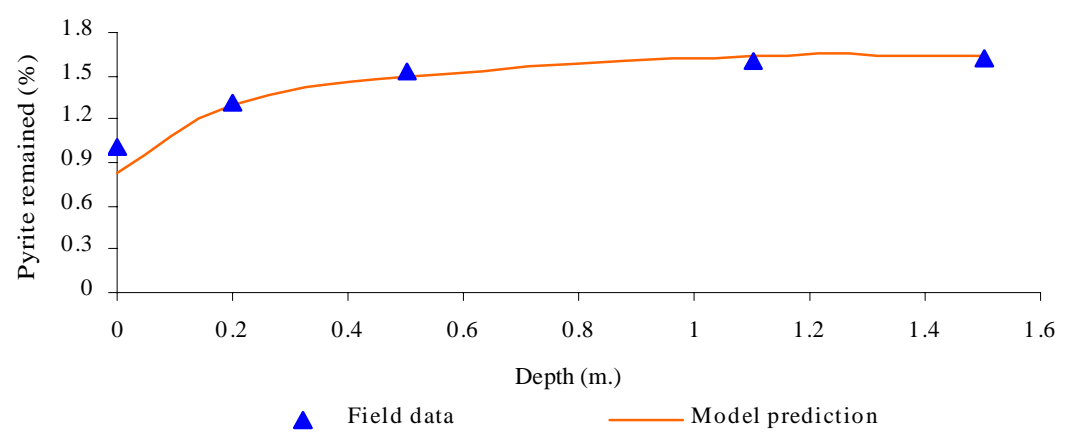

Fig. 5: Comparison of the field data and modelling results of the fraction of pyrite remained as a function of depth for sample No. 3

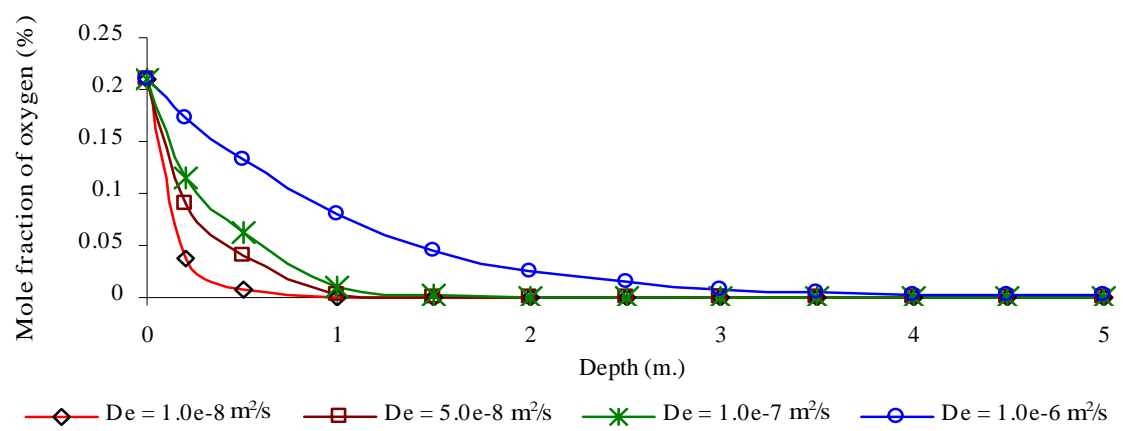

Fig. 6: Oxygen mole fraction vs. depth after 1 year of simulation represented for different effective diffusion coefficients ranged from $1 \times 10^{-8} \mathrm{~m}^{2} / \mathrm{s}$ to $1 \times 10^{-6} \mathrm{~m}^{2} / \mathrm{s}$

oxidation. Fig. 7 shows the sensitivity of the pyrite oxidation rate (illustrated as the fraction of pyrite remained) to the oxygen diffusion. Fig. 7 illustrates that the rate of pyrite oxidation greatly depends on the effective diffusion coefficient. An Increase in the effective diffusion coefficient significantly raised the amount of pyrite oxidation. For a depth of $0.25 \mathrm{~m}$ and under well-drained waste conditions with an effective diffusion coefficient of $1 \times 10^{-6} \mathrm{~m}^{2} / \mathrm{s}$, about $41 \%$ of pyrite was consumed after one year while with a diffusion value of $1 \times 10^{-8} \mathrm{~m}^{2} / \mathrm{s}$, the oxidised pyrite reduced to about $10 \%$ at the same simulation time and profile depth. In the second simulation, the sensitivity of the pyrite oxidation model to the oxidation times was considered. The effective diffusion coefficient was assumed to be a constant equal to $5 \times 10^{-8} \mathrm{~m}^{2} / \mathrm{s}$ oxygen did not diffuse more than $2.1 \mathrm{~m}$. (Fig. 6). Although not shown here, the smaller the simulation time, the higher the fraction of pyrite oxidised. When the simulation time is increased from 8 months to 15 months, the fraction of pyrite remained decreased from $1.49 \%$ to $1.35 \%$ for a given depth of $0.5 \mathrm{~m}$. Furthermore, a close agreement between the model predictions and the field data was obtained for an oxidation time of 12 months.
A geophysical survey using VLF method was performed on 6 profiles in the downstream of the waste dump in order to investigate the likely polluted zones due to leaching from the waste dump. The measured data was then processed by the use of RAMAG computer-based software (RAMAG instruction manual, 2002). Although not given here, the results of interpretation detected two polluted zones. Furthermore, the Geo-electrical survey incorporating lipole-lipole array and time-laps technique was carried out for a time period of 6 months in order to consider time dependence transportation of pollutants leached from the waste dump. A computer model called RES2DINV (RES2DINV Manual, 2002) was used to perform an inverse modeling on the measured Geo-electrical data. As it is evident from Fig. 8, the results of inverse modeling and time-laps method successfully showed the pollutant transportation process. A combined geophysical-mathematical model was also presented to investigate the transportation of the pollutants through the downstream of the waste dump. A one-dimensional advection-dispersion transport equation was used to simulate the pollutant transportation process. This equation can be written as (Reddi and Inyang, 2000): 

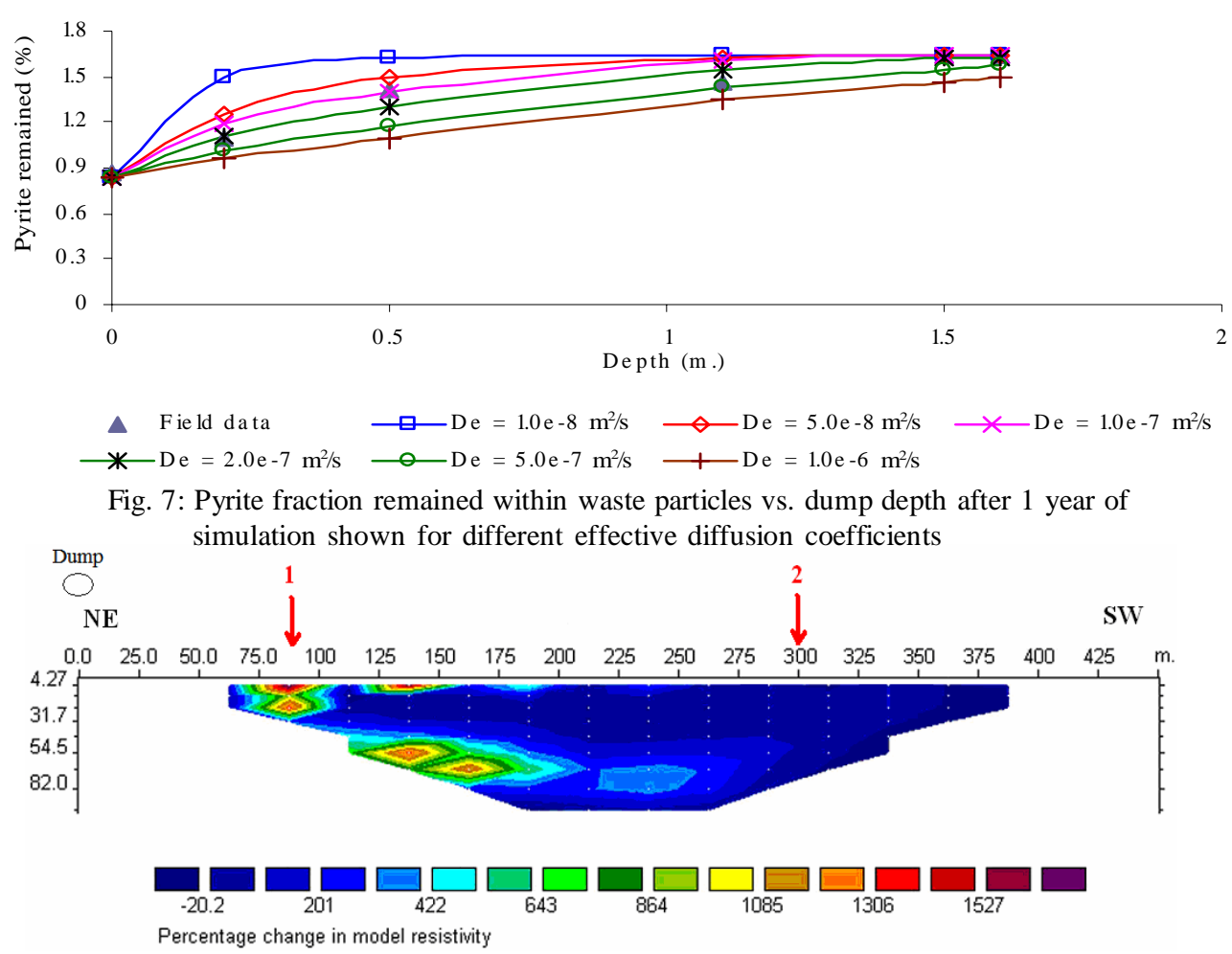

Fig. 8: Results of geo-electrical inverse modelling incorporating time-laps method showing the pollutant transportation process observed at Alborz-Sharghi coal washing waste dump

$\frac{\partial C}{\partial t}=D_{L} \frac{\partial^{2} C}{\partial x^{2}}-v_{X} \frac{\partial C}{\partial x}$

where,

$D_{L}=$ longitudinal dispersion coefficient $\left(\mathrm{m}^{2} / \mathrm{s}\right)$;

$v_{x}=$ average ground water velocity in the x-direction $(\mathrm{m} / \mathrm{s})$;

$C$ = contaminant concentration $\left(\mathrm{mol} / \mathrm{m}^{3}\right)$;

$x=$ distance in the $\mathrm{x}$-direction $(\mathrm{m})$;

$t=$ time (s).

An analytical equation for solving Eq. 8 can be expressed as follows (Reddi and Inyang, 2000):

$$
C(x, t)=\frac{C_{0}}{2}\left\{\begin{array}{l}
\operatorname{erfc}\left(\frac{x-v_{X} t}{2 \sqrt{D_{L} t}}\right)+ \\
\exp \left(\frac{v_{X} x}{D_{L}}\right) \operatorname{erfc}\left(\frac{x+v_{X} t}{2 \sqrt{D_{L} t}}\right)
\end{array}\right\}
$$

where,

$\mathrm{C}(\mathrm{x}, \mathrm{t})=$ contaminant concentration at any point and time $\left(\mathrm{mol} / \mathrm{m}^{3}\right)$;

$\mathrm{C}_{0}=$ source concentrDNRQQ $\left.\mathrm{mol} / \mathrm{m}^{3}\right)$.

erfc $=$ complement of the error function.

The complement of the error function is given in terms of its argument $\beta$ as follows (Freeze and Cherry, 1979):

$\operatorname{erfc}(\beta)=1-\operatorname{erf}(\beta)=1-\left(\frac{2}{\sqrt{\pi}}\right) \int_{0}^{\beta} e^{-u^{2}} d u$

Values of the error function, $\operatorname{erf}(\beta)$, and its complement, $\operatorname{erfc}(\beta)$, for different amounts of the argument $\beta$ can be obtained from specific tables (Reddi and Inyang, 2000).

The combined effect of molecular diffusion and mechanical dispersion is named hydrodynamic dispersion and can be formulated as:

$$
D_{L}=\alpha_{L} v_{X}+D_{\text {dif }}
$$

where,

$\alpha_{L}=$ longitudinal dispersivity of porous medium (m); 
$D_{\text {dif }}=$ molecular diffusion coefficient $\left(\mathrm{m}^{2} / \mathrm{s}\right)$

The predictions made by the geophysical modelling were checked by comparison with the analytical Eq. 9 incorporating advection-dispersion processes. As illustrated in Fig. 8, the point 1 ( $85 \mathrm{~m}$ from dump) and point 2 (300 m. from dump) were selected to calculate the concentration of sulphate as a major contaminant produced by pyrite oxidation process. The source concentration of sulphate is $0.6 \mathrm{~mol} / \mathrm{L}$. The effective diffusion coefficient $D_{\text {dif }}$ is $10^{-9} \mathrm{~m}^{2} / \mathrm{s}$. The dispersivity $\left(\alpha_{L}\right)$ is $5 \mathrm{~m}$. The pore-water flow velocity $\left(v_{x}\right)$ was $1.382 \times 10^{-5} \mathrm{~m} / \mathrm{s}$. This velocity was calculated from the difference of two elapsed times of the subsequent geoelectrical measurements and difference in contaminant movement in these times. The problem was solved using Eq. 9 and sulphate concentrations calculated in points 1 and 2 were 0.06 and $0 \mathrm{~mol} / \mathrm{L}$. As Fig. 8 shows, the sulphate concentration plume predicted by the geophysical modelling did not reach to the point 2; describing a close agreement between the mathematical modeling and the geophysical modelling in the prediction of contaminant transport associated with the coal waste dump. The present numerical model for describing pyrite oxidation, pollution generation and transportation from waste dump sites would facilitate the development of a waste dump rehabilitation and environmental management plan during the design stage of a coal washing plant.

\section{ACKNOWLEDGEMENTS}

The authors would like to express their deep appreciation to Alborz Sharghi Coal Company for supporting this research. The authors are grateful to the Faculty of Mining, Petroleum and Geophysics, Shahrood University of Technology for the financial and technical support provided for the M.Sc. thesis of the second author.

\section{REFERENCES}

Atkins, A. S.; Pooley, F. D., (1982). The effects of biomechanisms on acidic mine drainage in coal mining. Int. J. Mine Water., 1 (1), 31-44.

Cathles, L. M., (1979). Predictive capabilities of a finite difference model of copper leaching in low grade industrial sulfide waste dumps. Math. Geo., 11 (2), 175-191.

Cathles, L. M.; Apps, J. A., (1975). A model of the dump leaching process that incorporates oxygen balance, heat balance and air convection. Metall. Mater. Trans. B., 6 (4), 617-624

Davis, G. B.; Ritchie, A. I. M., (1986). A model of oxidation in pyritic mine wastes: part 1: Equations and approximate solution. Appl. Math. Model., 10 (5), 314-322.

Davis, G. B.; Doherty, G.; Ritchie, A. I. M., (1986). A model of oxidation in pyritic mine wastes: part 2: Comparison of numerical and approximate solutions. Appl. Math. Model., 10 (5), 323-329.

Destouni, G.; Malmstrom, M.; Berglund, S.; Lindgren, M., (1998). Modeling of acid mine drainage from waste rock and mill tailings. Technical Report, Division of Water Resources Engineering, State-of-the-Art Report, Report 3057, Department of Civil and Environmental Engineering, Royal Institute of Technology, Stockholm, Sweden, 25p.

Doulati Ardejani, F.; Singh, R. N.; Baafi, E. Y., (2004). Use of PHOENICS for solving one dimensional mine pollution problems. The PHOENICS Journal: Computational Fluid Dynamics and its applications., 16, 1-23.

Edwards, J. S.; Ren, T. X.; Jozefowicz, R., (1995). Using computational fluid dynamics (CFD) to solve mine safety and health problems. APCOM xxv, technical proceedings, Application of computers and operations research in the minerals industries, Brisbane, Australia, 9-14 July, 41-47.

Elberling, B.; Nicholson, R. V.; Scharer, J. M., (1994). A combined kinetic and diffusion model for pyrite oxidation in tailings: a change in controls with time. J. Hydrol., 157 (1), 47-60.

Freeze, R. A.; Cherry, J. A., (1979). Groundwater, $1^{\text {st. Ed., }}$ Prentice-Hall Inc., Englewood Cliffs, 604.

Guedes de Carvalho, R. A.; Gonzalez Bega, C. G.; Martins Sampaio, M. N.; Neves, O.; Sol pereira, M. C., (1986). A study of the drainage of the pyrite mines of Aljustrel (Portugal). Int. J. Mine Water, 5 (2), 43-56.

Jaynes, D. B.; Rogowski, A. S.; Pionke, H. B., (1984a). Acid mine drainage from reclaimed coal strip mines, 1: Model description. Water Resour. Res., 20 (2), 233-242.

Jaynes, D. B.; Rogowski, A. S.; Pionke, H. B., (1984b). Acid mine drainage from reclaimed coal strip mines, 2: Simulation results of model. Water Resour. Res., 20 (2), 243-250.

Lefebvre, R.; Gelinas, P. J., (1995). Numerical modeling of AMD production in waste rock dumps. In proceedings of Conference on mining and the environment, Sudbury, Ontario, 869-878.

Levenspiel, O., (1972). Chemical Reaction Engineering, $1^{\text {st. }}$ Ed., John Wiley, 578.

Lock, M. H., (1999a). Time lapse resistivity imaging inversion. In Proceedings of the $5^{\text {th. }}$ meeting of the Environmental and engineering society European section (EEGS-ES), Budapest, Hungary.

Lock, M. H., (1999b). Electrical imaging surveys for environmental and engineering studies. A practical guide to 2-D and 3D surveys, 58.

Patankar, S., (1980). Numerical heat transfer and fluid flow, $1^{\text {st. }}$ Ed., Taylor and Francis, 1-197.

Putti, M.; Yeh, W. W. G.; Mulder, W. A., (1990). A triangular finite volume approach with high-resolution upwind terms for the solution of groundwater transport equations. Water Resour. Res., 26 (12), 2865-2880.

RAMAG Instruction manual, Ver. 2.2., (2002). VLF survey planning and interpretation software. Encinitas, California.

Reddi, L. N.; Inyang, H. I., (2000). Geoenvironmental engineering principles and applications, $1^{\text {st. Ed., Marcel }}$ Dekker Inc, 113-155. 
RES2DINV Manual, Ver. 3.5., (2002). Rapid 2D resistivity and ip inversion., Geotomo software.

Rogowski, A. S.; Pionke, H. B.; Broyan, J. G., (1977). Modeling the impact of strip mining and reclamation processes on quality and quantity of water in mined areas: A review J. Environ. Qual., 6 (3), 237-244.

Singer, P. C.; Stumm, W., (1970). Acidic mine drainage: The rate determining, step. Science, 167 (3921), 1121-1123.

Singh, R. N.; Doulati-Ardejani, F., (2004). Finite volume discretisation for solving acid mine drainage problems. Arch. Min. Sci., 49 (4), 531-556.

Spalding, D. B., (1981). A general purpose computer program for multi-dimensional one- and two-phase flow. Math. Comput. Simulat., 23 (3), 267-276.

Versteeg, H. K.; Malalasekera, W., (1995). An Introduction to computational fluid dynamics, the finite volume method, $1^{\text {st. }}$ Ed., Prentice Hall, 257.
Walter, A. L.; Frind, E. O.; Blowes, D. W.; Ptacek, C. J.; Molson, J. W., (1994a). Modeling of multicomponent reactive transport in groundwater, 1: Model development and evaluation. Water Resour. Res., 30 (11), 3137-3148.

Walter, A. L.; Frind, E. O.; Blowes, D. W.; Ptacek, C. J.; Molson, J. W., (1994b). Modelling of multicomponent reactive transport in groundwater, 2: Metal mobility in aquifers impacted by acidic mine tailings discharge. Water Resour. Res., 30 (11), 3149-3158.

Williams, R. E.; Baldwin, J.; Ralston, D. R., (1979). Coping with mine drainage regulations. In Proceedings of the $1^{\text {st. }}$ International Mine Drainage Symposium, Denver, Colorado, $184-218$.

Wunderly, M. D.; Blowes, D. W.; Frind, E. O.; Ptacek, C. J., (1996). Sulfide mineral oxidation and subsequent reactive transport of oxidation products in mine tailings impoundments: A numerical model. Water Resour. Res., 32 (10), 3173-3187.

\section{AUTHOR (S) BIOSKETCHES}

Doulati Ardejani, F., Ph.D., Associate professor, Faculty of Mining, Petroleum and Geophysics, Shahrood University of Technology, Shahrood, Iran. Email: fdoulati@shahroodut.ac.ir

Jodieri Shokri, B., M.Sc. Shahrood University of Technology, Faculty of Mining, Petroleum and Geophysics, Shahrood University of Technology, Shahrood, Iran. Email: behshad_jodeiri@yahoo.com

Moradzadeh, A., Ph.D., Associate professor, Faculty of Mining, Petroleum and Geophysics, Shahrood University of Technology, Shahrood, Iran. Email: amoradzadeh@shahroodut.ac.ir

Soleimani, E., Ph.D., Assistant professor, Faculty of Chemistry, Shahrood University of Technology, Shahrood, Iran. Email: es_soleimani@yahoo.com

Ansari Jafari, M., Ph.D., Assistant professor, Faculty of Mining, Petroleum and Geophysics, Shahrood University of Technology, Shahrood, Iran. Email: majidansarijafari@gmail.com

This article should be referenced as follows:
Doulati Ardejani, F.; Jodieri Shokri, B.; Moradzadeh, A.; Soleimani, E.; Ansari Jafari, M., (2008). A combined
mathematical geophysical model for prediction of pyrite oxidation and pollutant leaching associated with a coal
washing Waste dump. Int. J. Environ. Sci. Tech., 5 (4), 517-526.

